\section{Novel Staining Method for Transmission Electron Microscopic Investigations of Semicrystalline Polyesters}

\section{M. Huong, ${ }^{\dagger}$ M. Drechsler, ${ }^{\dagger}$ H.-J. Cantow, ${ }^{\dagger}$ and M. Möller",t}

Institute of Macromolecular Chemistry and Freiburg Materials Research Center (FMF), Stefan-Meier-Strasse $31 A$, University of Freiburg, D-7800 Freiburg, Germany, and Department of Chemical Technology, University of Twente, NL-7500 AE Enschede, The Netherlands

Received July 17, 1992

Revised Manuscript Received December 1, 1992

Introduction. The increasing interest in polyesters such as polylactide (PLA), poly ( $\epsilon$-caprolactone) (PCL) and their copolymers, polyglycolide (PGA), and poly ( $\beta$-hydroxyalkanoates), including poly( $\beta$-hydroxy butyrate) (PHB) and poly(hydroxy butyrate-co-hydroxy valerate) $(\mathrm{P}(\mathrm{HB} / \mathrm{HV}))$, as biocompatible and biodegradable materials promotes a general interest in the morphological characterization of the semicrystalline polyesters. So far, it is known that the degree of crystallinity plays an important role in the degradation and drug-release properties of biomaterials.1,2 Electron microscopy has been intensively used in order to visualize the morphology of semicrystalline polyesters. While scanning electron microscopy only reveals textures of original or etched surfaces, ${ }^{3,4}$ transmission electron microscopy (TEM) allows us to visualize the fine morphology of semicrystalline polymers. 5

There are several approaches to improve contrast in TEM images of semicrystalline polyesters. Shadowing with a heavy metal, which is able to accentuate surface topography, has been proven to be useful in contrast enhancement. Single crystals or crystals from a suspension can be shadowed with chromium, ${ }^{6}$ with carbon/platinum, ${ }^{7,8}$ or with platinum/palladium..$^{9,10}$

However, for the observation of the supermolecular structure in bulk, it is necessary to differentiate the crystalline phase, in the form of lamellar crystals, for example, from the amorphous phase, either by etching or staining the disordered regions of the polymers. Slight etching of melt-crystallized $\mathrm{PHB}$ and $\mathrm{P}(\mathrm{HB} / \mathrm{HV})$ copolymer surfaces by means of methylamine, which preferentially diffuses into and attacks the amorphous regions, followed by replication showed the underlying microstructure.10 While shadowing the specimen surface with heavy metals or producing a surface replica can only reveal the morphology of the surface, staining is suitable for imaging of the morphology in bulk.

The best known staining methods for polyesters are twostage procedures, namely, (1) introduction of the reactive group and (2) oxidization of this group with osmium tetroxide $\left(\mathrm{O}_{\mathrm{BO}}\right)$. The treatment of semicrystalline polyesters with hydroxylamine or hydrazine vapor leads to the formation of hydroxamic acid and acid hydrazide, 11 respectively. These compounds can reduce osmium tetroxide to osmium and osmium oxides, which give rise to the dark appearance of the phases containing polyesters in a polymer dispersion. ${ }^{11,12}$ However, the handling with hydroxylamine or hydrazine causes the main disadvantage of this method. Hydroxylamine is instable and has to be prepared freshly from sodium methylate and hydroxyl-

\footnotetext{
+ University of Freiburg.

¿ University of Twente.
}

amine chlorohydrate in methanol. The use of hydrazine is dangerous because it is highly carcinogenic.

Wegner et al. ${ }^{13,14}$ substituted hydroxylamine with allylamine whose amine group reacts with the ester group of the polyester. The double bonds contained in allylamine molecules are susceptible to $\mathrm{O}_{8} \mathrm{O}_{4}$ vapor in a subsequent reaction. Due to the osmium deposition in amorphous regions, good images of polyester lamellae could be obtained. The handling with allylamine is less dangerous, but degradation of the polyesters by amine compounds ${ }^{10,15}$ occurs. It is therefore necessary to remove the excess of allylamine by applying a weak vacuum. In practice, efficient staining is tedious and difficult to be reproduced in a reliable manner.

It is obvious that the oxidation power of $\mathrm{O}_{8} \mathrm{O}_{4}$, one of the first reagents successfully applied to polymer staining, is not strong enough for polyesters. Treatment with ruthenium tetroxide $\left(\mathrm{RuO}_{4}\right)$, a much stronger oxidation reagent, ${ }^{16}$ leads to a simultaneous staining of polyester and polyethylene in blends. ${ }^{17}$

In this work, we present a new, specific staining method for semicrystalline polyesters based on the reduction of the ester bonds by borane, followed by oxidation with osmium tetroxide. This method is easy to reproduce and can be applied to different kinds of semicrystalline polymers, which contain reducible groups. The results of the two staining methods using borane $/ \mathrm{OBO}_{4}$ or $\mathrm{RuO}_{4}$ are compared to each other in order to find out the best suitable method for staining of polyesters.

Experimental Section. Poly(L-lactide) (PLLA; trademark Resomer L207 from Boehringer Ingelheim), meltcrystallized samples of poly( $\beta$-hydroxy butyrate) (trademark BIOPOL from ICI), and poly(e-caprolactone) (trademark TONE 787 from Union Carbide) were used.

Osmium tetroxide (Science Services) was dissolved in distilled methanol $(4 \% \mathrm{w} / \mathrm{v})$. The ready-to-use solution was stored in a closed, dark bottle at $-30^{\circ} \mathrm{C}$.

Bulk samples of the polyesters were trimmed for microtoming before they were exposed at $30-35^{\circ} \mathrm{C}$ for $0.5-10 \mathrm{~h}$ to the vapor phase of $2.5 \mathrm{~mL}$ of a borane-dimethyl sulfide complex $\left(\mathrm{BH}_{3} \cdot \mathrm{S}\left(\mathrm{CH}_{3}\right)_{2}, \mathrm{BMS}\right.$; Aldrich) in a small, grind-sealing glass. After removing BMS, the samples were subsequently stored for further 8-10 h in the oven in order to evaporate the excess of dimethyl sulfide. The effect of hydrolysis on staining quality was studied by storing simultaneously some BMS-treated samples at $35^{\circ} \mathrm{C}$ for the same time period over water in another grind-sealing glass.

Subsequently, all samples were put for 2 days at $-30^{\circ} \mathrm{C}$ and several hours at room temperature into an $\mathrm{OsO}_{4}$ solution. After staining, the samples were washed with water and dried in air.

For comparison, some samples were stained with $\mathrm{RuO}_{4}$ vapor according to the description given elsewhere. ${ }^{18}$

From the stained samples, ultrathin sections of 50-70$\mathrm{nm}$ thickness were cut at room temperature with an Ultracut E ultramicrotome (Leica), using a diamond knife.

Images were taken with a Zeiss CEM 902 electron microscope operated at $80 \mathrm{kV}$.

Results and Discussion. From several commercially available borane compounds, the borane-dimethyl sulfide complex (BMS) was chosen as the reducing agent. Compared to other borane complexes, borane-dimethyl sulfide possesses a vastly improved air stability and can be easily handled, making it a very versatile reagent for the reduction of organic functional groups.19

Brown et al. demonstrated the application of BMS in the selective reduction of carbozylic esters, ${ }^{20}$ primary 
amides, ${ }^{21}$ tertiary and secondary amides, ${ }^{22}$ and nitriles. ${ }^{23}$ A dramatic increase in the reduction rate was observed when dimethyl sulfide was removed from the reaction mixture. ${ }^{24}$ Other authors have been successful in using borane-dimethyl sulfide as a selective reducing agent for formamide ${ }^{25}$ and for $\alpha$-hydroxy esters. ${ }^{26}$ The reduction is highly selective, relatively insensitive to polar substituent effects, can tolerate many substituents, and is efficiently reactive toward sterically hindered groups. ${ }^{24}$

The staining ability of this new method toward polyesters could be macroscopically recognized by the fact that samples gradually become black during storage in $\mathrm{OsO}_{4}$, due to the deposition of fine, black particles of oxidation products. Samples which were stored over water degraded as indicated by the loss of an external layer and became black only at room temperature. In contrast, samples which were stored in air became black even at a temperature of $-30^{\circ} \mathrm{C}$. According to Brown, ${ }^{20} \mathrm{BMS}$ reduces esters to an intermediate, presumably the dialkoxyborane:

$$
\mathrm{R}^{1} \mathrm{COOR}^{2}+\mathrm{H}_{3} \mathrm{~B} \cdot \mathrm{S}\left(\mathrm{CH}_{3}\right)_{2} \rightarrow \mathrm{R}^{1} \mathrm{CH}_{2} \mathrm{OBHOR}{ }^{2}+\left(\mathrm{H}_{3} \mathrm{C}\right)_{2} \cdot \mathrm{S}
$$

The dialkoxyborane can easily be hydrolyzed to give the corresponding alcohols. Hydrolytic degradation of the polyester can explain why a surface layer of the samples easily peeled off after storage over water. Hydrolysis in the case where the samples were stored in air at $35^{\circ} \mathrm{C}$ was neglectable. Hydroborated polyesters were readily oxidized by $\mathrm{OsO}_{4}$ even at $-30^{\circ} \mathrm{C}$. The preservation of a trimmed, smooth surface of the samples appears to be the result of the direct conversion of the borane addition products with osmium, suggesting that no degradation occurred. Possibly, cross-linking contributes to the sample integrity. The experiments demonstrated that hydrolysis of borane-treated samples before staining with $\mathrm{OsO}_{4}$ was not necessary.

Up to $-70^{\circ} \mathrm{C}, \mathrm{OsO}_{4}$ possesses no oxidation capability. ${ }^{27}$ Compared to the reaction rate at room temperature, the oxidation and cross-linking capability of $\mathrm{OsO}_{4}$ at $-30^{\circ} \mathrm{C}$ cannot be completely suppressed but strongly reduced. A reduction of the rates of oxidation and cross-linking is favorable to the diffusion of $\mathrm{OsO}_{4}$ into the sample. During the storage of a BMS-treated sample in $\mathrm{OsO}_{4}$ solution at low temperature $\left(-30^{\circ} \mathrm{C}\right)$ within $40 \mathrm{~h}, \mathrm{OsO}_{4}$ molecules could therefore diffuse deeply into the sample.

Treatment with $\mathrm{BMS} / \mathrm{OsO}_{4}$ or with $\mathrm{RuO}_{4}$ leads to a desired sample hardening which helps to avoid timeconsuming cryomicrotoming and allows the preparation of smooth sections of less than 100-nm thickness at room temperature. It could be noted that well-stained places became more resistant to damages caused by the electron beam. This observation is also consistent with the concept that $\mathrm{RuO}_{4}$ and $\mathrm{OsO}_{4}$ fix and stain through chemical crosslinking or bridging. 5,16

Figure 1a shows that fine structural details of a meltcrystallized poly ( $\beta$-hydroxy butyrate) $\left(T_{\mathrm{g}}=0^{\circ} \mathrm{C}\right.$ ) can be revealed by staining with $\mathrm{BMS} / \mathrm{OsO}_{4}$. For comparison, Figure $1 \mathrm{~b}$ gives an electron micrograph of the sample but stained with $\mathrm{RuO}_{4}$. The TEM images of $\mathrm{RuO}_{4}$-stained polyethylene/polyester blends ${ }^{17}$ had shown that the vigorous oxidation agent $\mathrm{RuO}_{4}$ is able to stain both polyethylene and polyesters in a one-step procedure. In Figure 1 , the semicrystalline polyester was more homogeneously

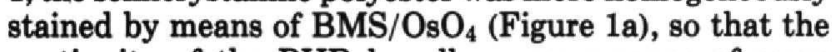
continuity of the PHB lamellae over a range of some microns can be seen. The lamellar thickness is approximately $5 \mathrm{~nm}$. In the $\mathrm{RuO}_{4}$-stained sample (Figure $1 \mathrm{~b}$ ), only small parts of the lamellae of approximately $200 \mathrm{~nm}$
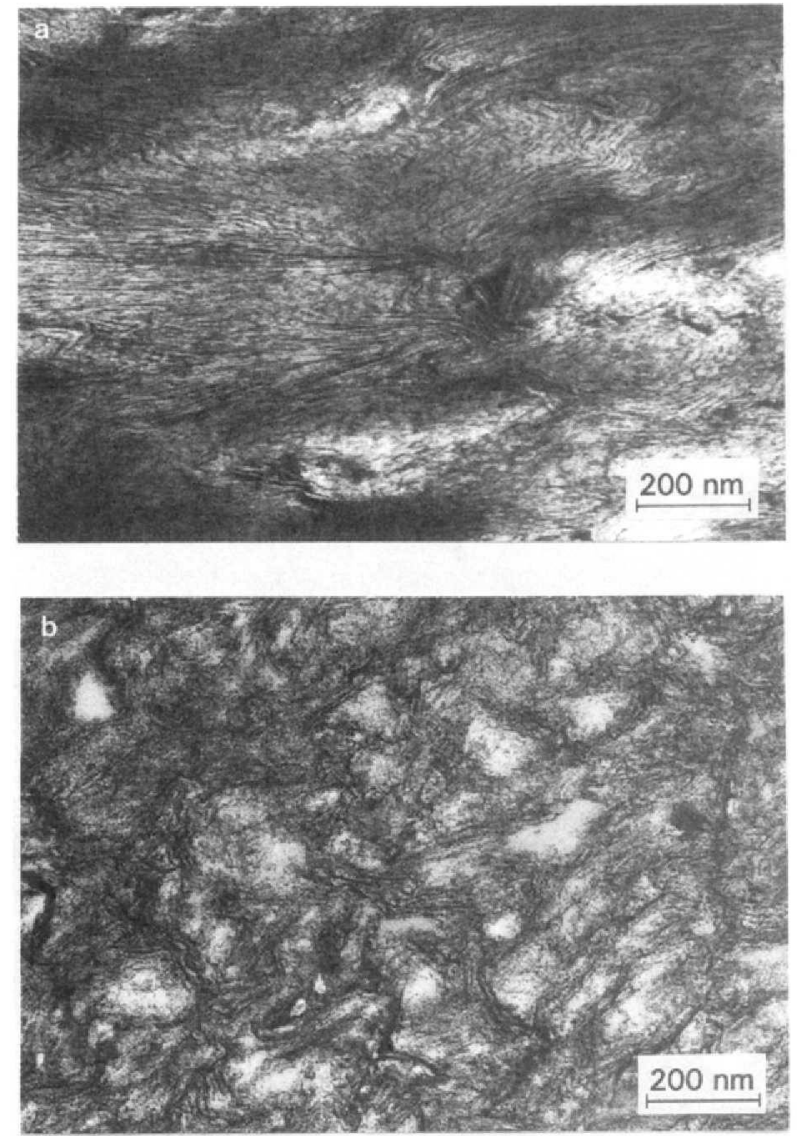

Figure 1. TEM micrographs of a melt-crystallized PHB: (a) stained by $\mathrm{BMS} / \mathrm{OsO}_{4}$; (b) stained by $\mathrm{RuO}_{4}$.

in length were heavily stained. In the immediate neighborhood of the strongly stained areas are places that were not stained at all.

The differences in staining homogeneity may be explained by the different diffusion/oxidation balance of $\mathrm{OsO}_{4}$ and $\mathrm{RuO}_{4}$ molecules. When a semicrystalline polymer structure consists of crystalline, mobile-amorphous, and rigid-amorphous regions, ${ }^{28,29}$ the reaction of the sample with the staining agent begins at the most reactive, rigid-amorphous regions. Due to their stronger oxidation potential, $\mathrm{RuO}_{4}$ molecules oxidize and crosslink a polymer sample as soon as they diffuse into the sample. The cross-linking takes place at the early stage, which possibly causes the formation of a diffusion barrier to other $\mathrm{RuO}_{4}$ molecules. As a result, deposits of the $\mathrm{RuO}_{2}$ crystals are concentrated in the most reactive, rigidamorphous regions. ${ }^{29,30} \mathrm{On}$ the other side, the oxidation and cross-linking caused by $\mathrm{OsO}_{4}$ proceed less vigorously, and on the long term more selectively, enabling a more homogeneous diffusion of $\mathrm{OsO}_{4}$ molecules into the amorphous and rigid-amorphous regions. Deposits of the $\mathrm{OsO}_{4}$ staining are observed therefore at noncrystalline regions of semicrystalline polymers. ${ }^{5}$

The $\mathrm{BMS} / \mathrm{OsO}_{4}$ staining is advantageous for the visualization of the lamellar morphology of polyesters with very different glass transition temperatures: poly( $\epsilon-$ caprolactone) $\left(T_{\mathrm{g}}=-60^{\circ} \mathrm{C}\right)$ (Figure 2) and poly(L-lactide) $\left(T_{\mathrm{g}}=50^{\circ} \mathrm{C}\right)$ (Figure 3 ). Because the treatment with BMS/ $\mathrm{OsO}_{4}$ leads to hardening of the sample, ultramicrotoming of poly( $\epsilon$-caprolactone) is possible at room temperature, despite its low glass transition temperature. In Figure 2, the lamellar structure of the PCL can be recognized very clearly because $\mathrm{OsO}_{4}$ reacted almost completely with the chains in noncrystalline phases, resulting in a high contrast. 


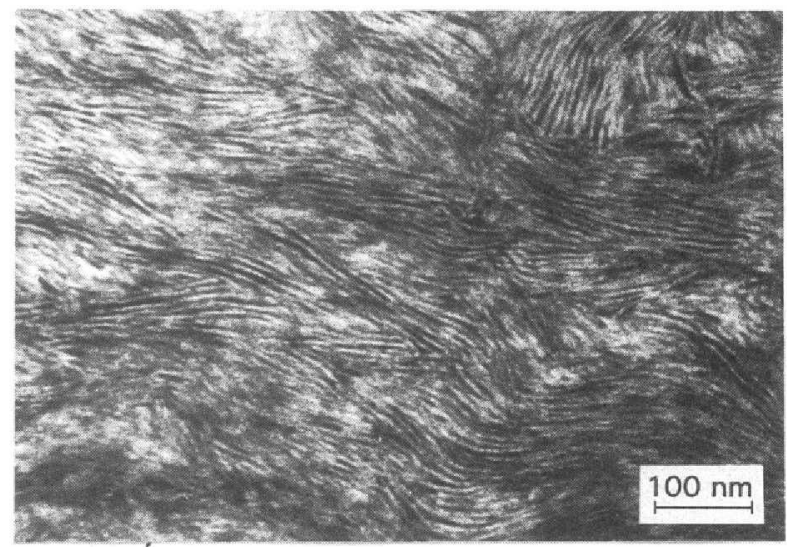

Figure 2. TEM micrograph of PCL stained by $\mathrm{BMS} / \mathrm{OsO}_{4}$.

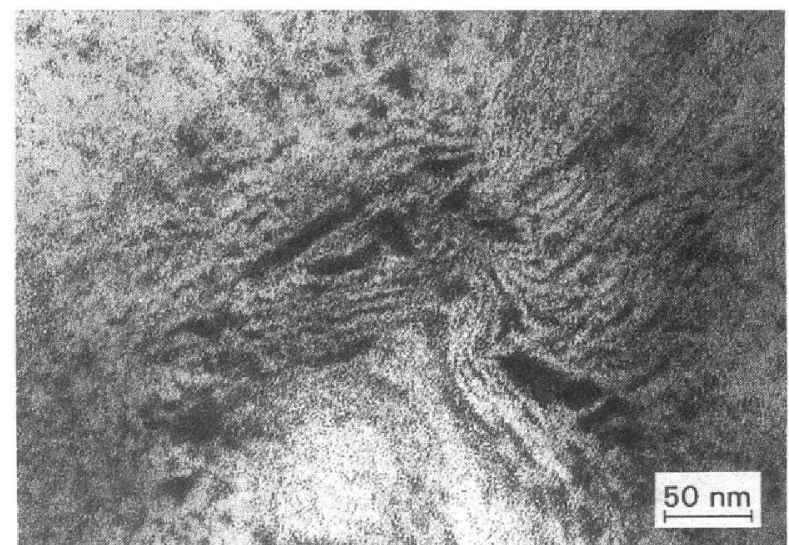

Figure 3. TEM micrograph of PLLA stained by $\mathrm{BMS} / \mathrm{OsO}_{4}$.

Staining of poly(L-lactide) is usually difficult because diffusion of low-molecular compounds into the polymer depends strongly on the glass transition temperature of the polymer matrix. This problem can be solved during the BMS treatment, simply by increasing the reaction temperature, the reaction time, and/or the amount of BMS. Figure 3 shows a highly magnified micrograph of an ultrathin PLLA section. Compared to the contrast available with PCL or PHB samples, the contrast obtained in this case is weaker but still allows a clear recognition of the morphology. The granular structure visible in higher resolution micrographs may be explained by precipitation of $\mathrm{OsO}_{4}$ reaction products.

Conclusion. Reduction of ester groups by boranedimethyl sulfide vapor, followed by oxidation with $\mathrm{OsO}_{4}$, provides a novel and helpful staining technique for morphological TEM investigations of semicrystalline polyesters such as PCL, PLLA, and PHB. It appears likely that this staining technique may be applied for many other polymers which contain ester, amide, or nitrile groups. Both $\mathrm{BMS} / \mathrm{OsO}_{4}$ and $\mathrm{RuO}_{4}$ staining methods are effective in hardening the samples. The TEM images showed that $\mathrm{BMS} / \mathrm{OsO}_{4}$ staining is more homogeneous than $\mathrm{RuO}_{4}$ staining and is able to reveal fine morphological details of semicrystalline polyesters.

Acknowledgment. Our appreciations go to Dr. M. Kunz for his constructive discussions and manuscript correction. We thank E. Schill-Wendt for printing the photographs and the Graduiertenkolleg Polymerwissenschaften, University Freiburg, for supporting D.M.H. with a doctoral scholarship.

\section{References and Notes}

(1) Pitt, C. G.; Gratzl, M. M.; Jeffcoat, A. R.; Zweidinger, R.; Schindler, A. J. Pharm. Sci. 1979, 68, 1534-1538.

(2) Akhtar, S.; Pouton, C. W.; Notarianni, L. J. Polymer 1992, 33 , 117-126.

(3) Kalb, B.; Pennings, A. J. Polymer 1980, 21, 607-612.

(4) Phillips, P. J.; Rensch, G. J.; Taylor, K. D. J. Polym. Sci., Polym. Phys. Ed. 1987, 25, 1725-1740.

(5) Sawyer, L. C.; Grubb, D. T. Polymer Microscopy; Chapman and Hall: New York, 1987.

(6) Alper, R.; Lundgren, D. G.; Marchessault, R. H.; Cote, W. A. Biopolymers 1963, 1, 545-556.

(7) Ellar, D.; Lundgren, D. G.; Okamura, K.; Marchessault, R. H. J. Mol. Biol. 1968, 35, 489-502.

(8) Fischer, E. W.; Sterzel, H. J.; Wegner, G. Kolloid Z. Z. Polym. $1973,251,980-990$.

(9) Barham, P. J.; Keller, A.; Otun, E. L.; Holmes, P. A. J. Mater. Sci. 1984, 19, 2781-2794.

(10) Organ, S. J.; Barham, P. J. J. Mater. Sci. Lett. 1989, 8, 621623.

(11) Kanig, G.; Neff, H. Colloid Polym. Sci. 1975, 253, 29-31.

(12) Distler, D.; Kanig, G. Colloid Polym. Sci. 1978, 256, 10521060.

(13) Wegner, G.; Zhu, L.-L.; Lieser, G. Makromol. Chem. 1981, 182, 231-235.

(14) Zhu, L.-L.; Wegner, G. Makromol. Chem. 1981, 182, 36253638.

(15) Welland, E. L.; Stejny, J.; Halter, A.; Keller, A. Polym. Commun. 1989, 30, 302-304.

(16) Trent,J.S.; Scheinbein, J. I.; Couchman, P. R. Macromolecules $1983,16,589-598$.

(17) Huong, D. M.; Drechsler, M.; Cantow, H.-J.; Möller, M. Fourth World Biomater. Congr. Trans, 1992, 616.

(18) Montezinos, D.; Wells, B. G.; Burns, J. L. J.Polym. Sci., Polym. Lett. Ed. 1985, 23, 421-425.

(19) Lane, C. F. Chem. Rev. 1976, 76 (6), 773-799.

(20) Brown, H. C.; Choi, Y. M. Synthesis 1981, 439-440.

(21) Brown, H. C.; Narasimhan, S.; Choi, Y. M. Synthesis 1981, 441-442.

(22) Brown, H. C.; Narasimhan, S.; Choi, Y. M. Synthesis 1981, 996-997.

(23) Brown, H. C.; Choi, Y. M.; Narasimhan, S. Synthesis 1981, 605-606.

(24) Brown, H. C.; Choi, Y. M.; Narasimhan, S. J. Org. Chem. 1982, $47,3153-3163$

(25) Krishnamurthy, S. Tetrahedron Lett. 1982, 23, 3315-3318.

(26) Saito, S.; Hasegawa, T.; Inaba, M.; Nishida, R.; Fujii, T.; Nomizu, S.; Moriwake, T. Chem. Lett. 1984, 1389-1392.

(27) White, D. L.; Andrews, S. B.; Faller, J. W.; Barrnett, R. J. BBA 1976, 436, 577-592.

(28) Suzuki, H.; Grebowicz, J.; Wunderlich, B. Makromol. Chem. $1985,186,1109-1119$

(29) Kunz, M.; Möller, M.; Heinrich,U.-R.; Cantow, H.-J.Makromol. Chem., Macromol. Symp. 1989, 23, 57-72.

(30) Huong, D. M.; Drechsler, M.; Möller, M.; Cantow, H.-J. J. Microsc. 1992, 166, 317-328. 